\title{
METHODS FOR SNOW MAPPING FROM METEOROLOGICAL SATELLITE IMAGERY OF THE QILIAN MOUNTAINS, NORTH-WEST CHINA
}

\section{(Abstract)}

by

Z.K. Liu

(Digital Image Processing Laboratory, Department of Radio Electronics, University of Science and Technology of China, Hefei, China)

and

\section{S.Y. Chang}

(Lanzhou Institute of Glaciology and Geocryology, Academia Sinica, Lanzhou, China)

\section{ABSTRACT}

A snow survey in north-west China has been carried out using meteorological satellite NOAA-9 imagery. A two-step geometric correction method is presented. The first step involves a large-scale geometric correction, and the second step concentrates on a small area of interest, using the control-point correction method. A high precision of geometric correction can be achieved by using this method. The snow-covered area of the Qilian Mountains basin is calculated.

\section{MULTI-SPECTRAL LANDSAT IMAGE MAPS OF ANTARCTICA}

\section{(Abstract)}

\author{
by
}

\author{
B.K. Lucchitta, K. Edwards, E.M. Eliason and J. Bowell
}

(U.S. Geological Survey, Flagstaff, AZ 86001, U.S.A.)

\begin{abstract}
The US Geological Survey is conducting a program to prepare digitally enhanced Multispectral Scanner (MSS) Landsat images of Antarctica. The goal is to furnish accurate planimetric, false-colour composite image maps in Lambert conformal conic projection for the following purposes: (1) to locate and delineate blue-ice areas for the collection of meteorites; (2) to produce special purpose maps showing selected features; (3) to provide synoptic views that aid in the detection and interpretation of glaciological features associated with the inland ice sheet, outlet glaciers, ice streams, and ice shelves; (4) to monitor changes in coastline and glacial features; (5) to enable the superposition and correlation of different types of digital cartographic data; and (6) to furnish spectral and (or) structural information in areas of limited bedrock outcrop to aid in regional geologic interpretation. Only the first four of these objectives are addressed here.

About 170 Landsat computer-compatible tapes covering Victoria Land, the coastline of West Antarctica, the Antarctic Peninsula, and other selected areas were assembled into false-color, multi-spectral, digital composites of band 4 (0.5 to $0.6 \mu \mathrm{m}$, green), band $5(0.6$ to $0.7 \mu \mathrm{m}$, red) and band $7(0.8$ to $1.1 \mu \mathrm{m}$, near infra-red). The tapes were subjected to routine image-processing procedures, such as noise removal and radiometric and geometric corrections. Further processing included haze removal and enhancement by linear stretching of individual MSS bands based on inspection of gray-value (digital-number) histograms. Saturation of snow-covered scenes in bands 4,5 , and 6 is a severe problem in Landsat MSS images of Antarctica and
\end{abstract}

makes many images unsuitable for multi-spectral work. We have developed special techniques to restore the saturated snow-and-ice information in these bands to overcome this problem.

The Landsat image maps have different formats, depending on their planned applications. An example of a planimetric image map is the one of the McMurdo Sound area; it is based on excellent ground control and processed at full spatial resolution. It comprises five complete and three partial 1:250 000 scale topographic quadrangles. One of these is the Convoy Range quadrangle which includes the Allan Hills meteorite-collection site. Blue-ice areas show exceptionally well on this quadrangle, and new information on blue-ice locations and delineations was obtained from it.

Thematic maps prepared for the Byrd Glacier area selectively show only rock or ice areas, thus depicting the location of desired features. Synoptic-view maps and mosaics provide information on flow lines associated with ice streams, the location of ice rises, ice rumples, and other possible grounded areas, and the location and extent of buried mountain ranges. Image maps which cover the same area at different times do show changes: a 10-year interval between Landsat images obtained in the Byrd Glacier area shows that crevasses had opened and rifts had drifted within the floating part of the glacier; measurements of the changed positions have yielded average velocities for glacier and ice-shelf movements in that area. The ease with which the dynamics of the coastline can be monitored on Landsat images is particularly useful, because such changes have implications for variations in world climate. 